\title{
SOLAR AND WIND STAND-ALONE POWER SYSTEM
}

\author{
Gennady Nikitenko, Evgeny Konoplev, Vladimir Salpagarov, Alexander Lysakov \\ Stavropol State Agrarian University, Russia \\ nikitenko_gv@mail.ru, konoplev82@mail.ru, s_lysakov@mail.ru
}

\begin{abstract}
The article considers a low-energy wind and solar stand-alone power system for agricultural consumers. The wind generator used is a $500 \mathrm{~W}$ dual magnetic synchronous generator, and its structural diagram, magnetic flux density distribution chart, mathematical modelling and the field test results are presented. The article also describes a linear drive solar panel tracker. The tracker structure and design and the field test results for a solar collector with the solar tracker are presented. A synchronous generator with a two-circuit magnetic system contains an external and internal circuit on which neodymium magnets, a magnetic core, additional poles are fixed. Between external and internal circuits the generator stator windings are arranged. The body of the synchronous generator, on which the external and internal magnetic circuits are fixed, is made of plastic. The excess energy produced by a synchronous generator with a double-circuit magnetic system is accumulated in the batteries, in case of lack of wind load, simultaneous operation of a synchronous generator with a double-circuit magnetic system and a battery through a power controlled transistor to the inverter is possible. Tracking system of the sun contains the sensor of position of the sun, two DC motors with gearboxes and retractable stocks, allowing to position the solar panels in two planes, horizontally and vertically depending on the position of the sun, allowing to increase the power generation of solar panels compared with the stationary arrangement of $40 \%$.
\end{abstract}

Keywords: wind power, solar power, power supply, hybrid system.

\section{Introduction}

Development of individual and farm enterprises, the constant rise in prices for traditional energy, the high cost of laying power lines forced to look for new ways to provide electricity to agricultural consumers of low power.

The most appropriate and promising option is the use of alternative energy sources, such as the wind and the sun, to supply electricity to agricultural consumers, remote from electric networks. The use of solar and wind energy for power supply to small consumers is discussed in the works of Razmjoo, A., Samikannu, R., Sun, W., Al-Dousari, A. and other authors [1-4].

The combined use of solar and wind energy can improve the energy efficiency of autonomous electric systems, reduce the cost of electricity generated and reduce the consumption of traditional energy carriers.

\section{Materials and methods}

To solve this problem, a wind-solar system of autonomous power supply [5] is developed, the block diagram of which is shown in Figure 1.

The autonomous power supply system uses a propeller-type wind turbine, synchronous generator with a two-circuit magnetic system [6], flexible solar panels with the possibility of bending to a certain angle, helium-type batteries are used, the control system is based on a programmable microcontroller Arduino Uno.

Wind-solar installation of autonomous power supply works as follows.

If the wind speed, that is, the power on the shaft of the windmill is sufficient to supply electricity to consumers, the installation works as follows. Torque from the turbine is fed to the multiplier and the one-way clutch, from which it is transmitted to the rotor of the synchronous generator, the generated voltage of the phases of the synchronous generator is supplied to the diode bridge, from which a constant voltage is supplied to the inverter. The inventor converts DC voltage to AC voltage, which is supplied to the voltage regulator, from which a stable AC voltage through relay reverse current is supplied in single-phase AC network voltage, from which electricity is supplied by stable consumers of electric energy of alternating voltage, and the battery is charged via the charge controller of the battery operated control system. Flexible solar panels are connected to the battery charge controller, the energy from which is also used to charge the batteries. In the event that the batteries are fully charged, the excess electricity generated from the flexible solar panels is supplied to the ballast load, 
thereby preventing overcharging of the batteries. Flexible solar panels are bent at a certain angle, thereby forming a solar energy concentrator that allows to convert the energy of the sun into electricity as much as possible. Flexible solar panels are located in the sun orientation device, which monitors the sun during the day and changes its position in order to maximize the concentration of solar energy on the surface of the flexible solar panels.

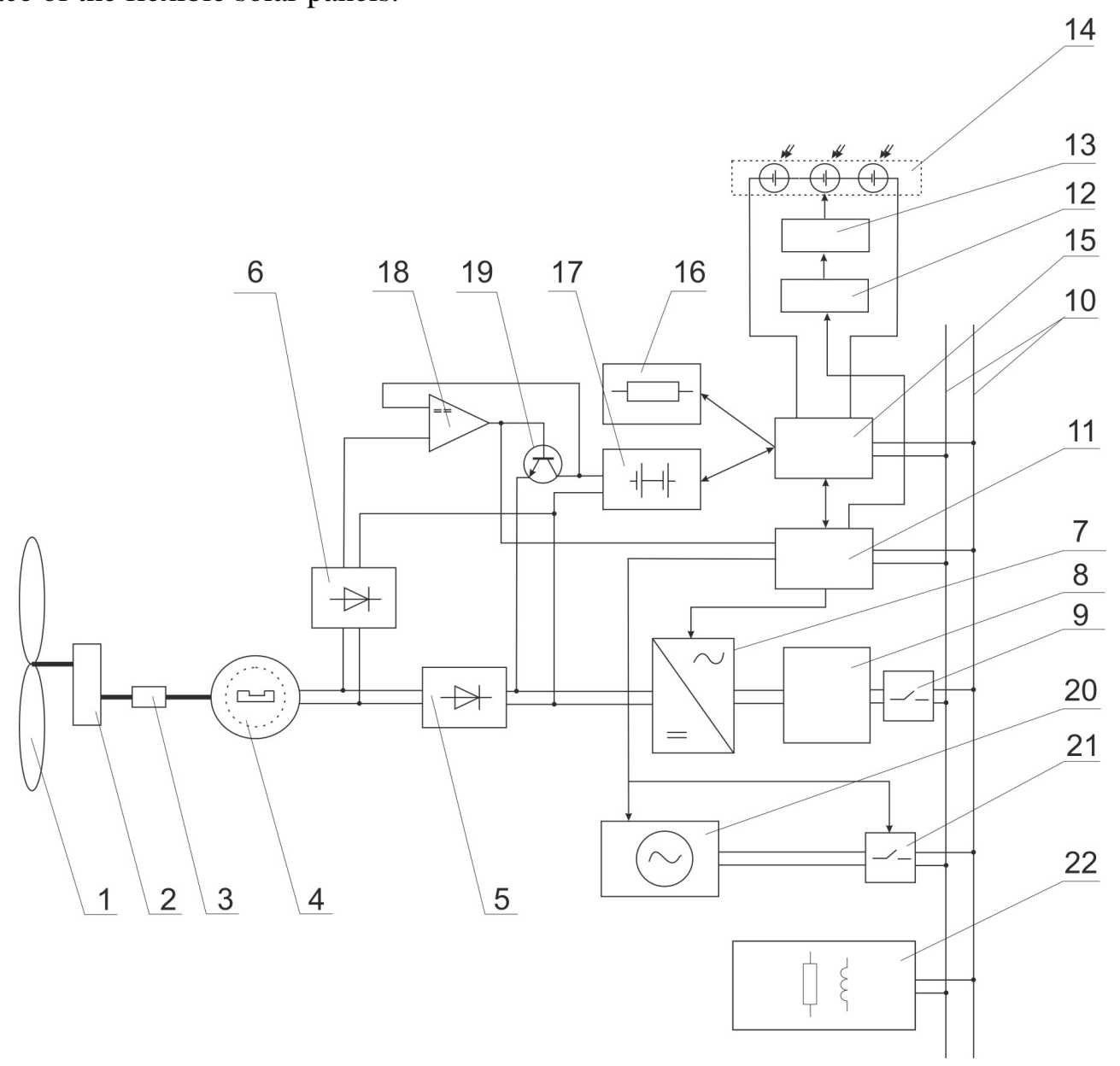

Fig. 1. Wind - solar system of Autonomous power supply to agricultural consumers:

1 - wind turbine; 2 - multiplier; 3 - overrunning clutch; 4 - synchronous generator; 5,6 - diode bridges; 7 - inverter; 8 - voltage stabilizer; 9 - reverse current relay; 10 - single-phase AC voltage network; 11 - control system; 12 - solar orientation system; 13 - sun orientation device; 14 - solar panels 15 - charge controller; 16 - ballast load; 17 - accumulator batteries 18 - voltage comparator;

19 - power transistor; 20 - petrol generator; 21 - relays; 22 - consumers of electric energy

If the wind speed is insufficient to power the consumers, the generated voltage from the phases of the synchronous generator is supplied to the diode bridge, from which the signal about the voltage level at the phases of the synchronous generator is supplied to the first input of the voltage comparator. The second input of the voltage comparator receives a signal that, if the voltage at the phases of the synchronous generator is greater than the voltage on the batteries, the output of the voltage comparator will be a logical zero, and the voltage comparator-controlled power transistor will be closed. If the voltage of the synchronous generator is less than the voltage of the batteries, then a logical unit will appear at the output of the voltage comparator, while opening of the collector-emitter transition of the power transistor, the voltage from the batteries through the power transistor and the voltage from the phases of the synchronous generator through the diode bridge will simultaneously arrive at the voltage inverter, thus, simultaneous power supply to consumers will be produced by the energy produced by the synchronous generator from the wind turbine and the energy accumulated in the batteries. The signal from the output of the voltage comparator enters the control system that controls the operation of the battery charge controller, in the case of a logical unit at the output of the voltage comparator, the battery charge controller is disconnected from the single-phase AC voltage network and the battery is 
charged only from flexible solar panels, otherwise, the battery charge controller is connected to a single-phase AC voltage network and the battery is charged both from a single-phase AC voltage network and from flexible solar panels through the battery charge controller. The voltage comparator works according to the algorithm of the built-in hysteresis loop, that is, the connection of batteries is made at a minimum level of voltage depending on the power of the currently connected consumers of electric energy at the phases of the synchronous generator, and the disconnection of the battery by means of a power transistor is made at a higher voltage level at the phases of the synchronous generator, this avoids the effect of "rattling, sticking" at approximately the same voltage levels in the phases of the synchronous generator and batteries, which facilitates the operation of the synchronous generator, battery charge controller.

If there is no wind, the synchronous generator does not produce electrical energy. The installation works as follows. At the output of the voltage comparator there will always be a logical unit, the battery charge controller will be disconnected from the single-phase AC voltage network, the battery charge will be produced by the energy obtained from flexible solar panels. The power transistor in this case will be opened and the voltage from the batteries through the collector-emitter transition of the power transistor is supplied to the voltage inverter, then to the voltage stabilizer and reverse current relay, from which the stabilized alternating voltage enters the single-phase AC voltage network.

In the absence of wind and discharged batteries the installation works as follows. When the minimum battery voltage (discharge) is reached, the signal is sent to the battery charge controller and then to the control system. The control system sends a start signal to the gasoline generator and connects it to a single-phase AC voltage network using a relay, while the battery charge controller is connected to a single-phase AC voltage network and charges the batteries due to the energy of the gasoline generator and the energy obtained from flexible solar panels, as well as from the control system, a signal enters the base of the power transistor and forcibly closes it, thereby disconnecting the battery from the voltage inverter. The operation of the gasoline generator is performed until the batteries are fully charged, then the signal from the control system to the base of the power transistor is removed, the gasoline generator is disconnected from the single-phase AC voltage network and stopped. Further the installation works in one of the modes described above. If in a given period of time there will be wind, that is, the synchronous generator will begin to produce electrical energy, it is possible to work together for the synchronous generator and the gasoline generator to supply electricity to consumers.

Increasing the energy characteristics of the autonomous power supply system on the basis of a wind power plant is possible by improving the energy characteristics (power, efficiency, specific metal content, etc.) of a synchronous permanent magnet generator through the use of a two-circuit magnetic system [6].

The general view of the generator is shown in Figure 2.

a)

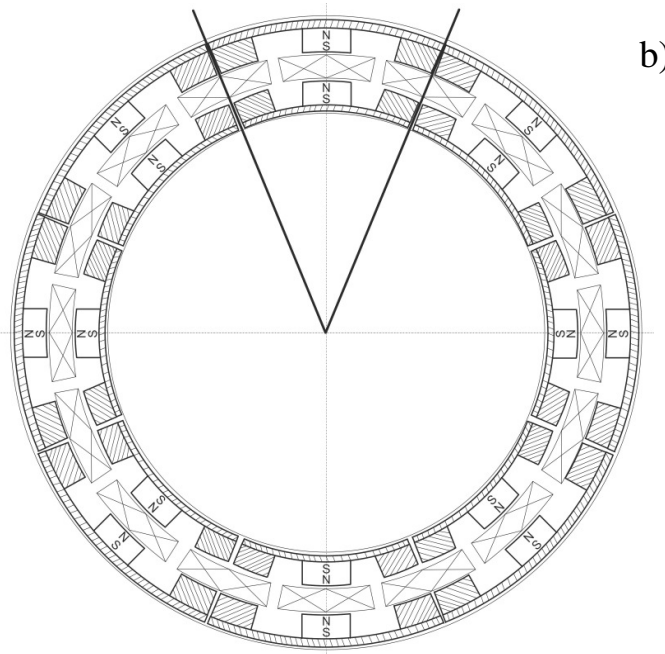

b)

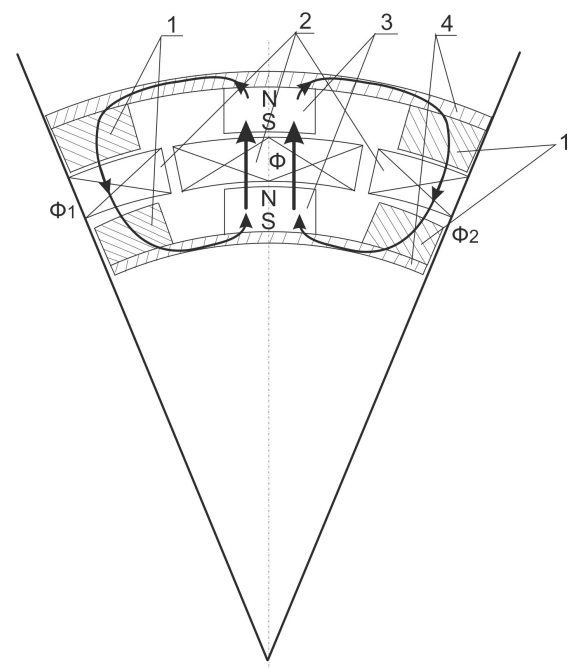

Fig. 2. General view of synchronous generator with two-circuit magnetic system (a) and generator sector with direction of magnetic fields (b) 
The generator contains 8 neodymium magnets in the external and internal circuit, between which the stator windings are fixed on a fixed base, which eliminates the use of a brush unit. The work of the generator is carried out by rotating the rotor, in which both permanent magnets and the magnetic core are fixed.

The following configuration of the synchronous generator is developed, on the basis of which the generator consists of additional poles 1, stator windings 2, permanent neodymium magnets 3 and a magnetic core (electrical steel) 4 .

The magnetic flux penetrates the stator winding located between the permanent magnets from the North to South, then through the magnetic core 4 and the additional poles 1 the magnetic flux passes through the winding located between the additional poles.

Introduction of an internal magnetic circuit can increase both the energy of the magnetic field in the stator windings, and the value of the magnetic flux and magnetic induction.

\section{Results and discussion}

Thus, the proposed system of autonomous power supply provides an increase in the utilization rate of the wind flow, uninterrupted power supply through the use of wind energy and accumulated in batteries.

The use of flexible solar panels, a solar orientation system and a solar orientation device makes it possible to use the energy of the sun, both for power supply to consumers of electric energy and for saving fuel for the gasoline generator, increases the energy intensity and power of the wind-solar installation of autonomous power supply.

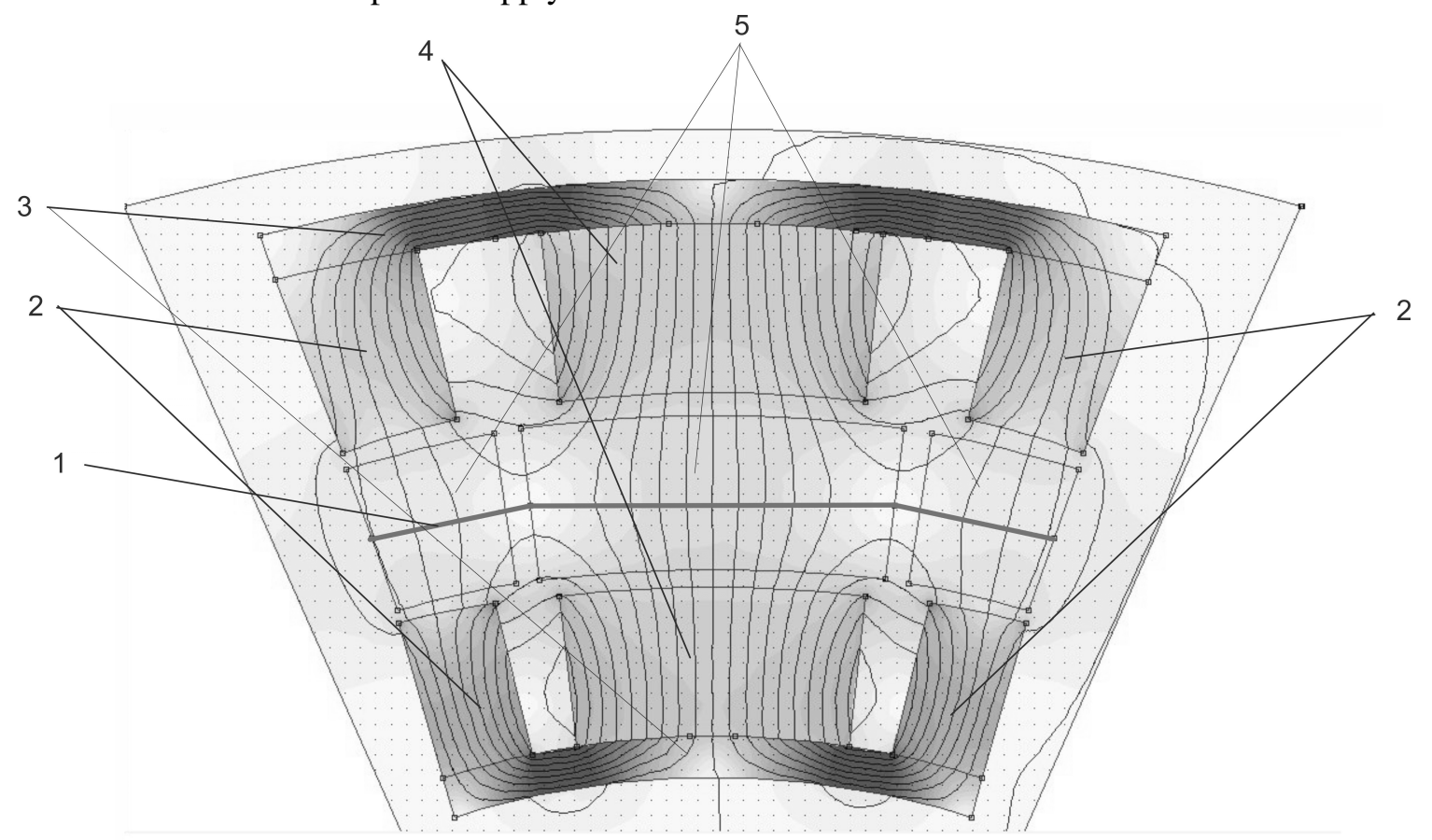

Fig. 3. Results of simulation of magnetic induction distribution in sector of synchronous generator with double-circuit magnetic system: 1 - section, in which the value of magnetic induction was measured; 2 - additional pole; 3 - magnetic core; 4 - permanent magnets; 5 - generator stator windings

The combined use of the energy obtained from the wind turbine, flexible solar panels, gasoline generator for power supply to consumers of electric energy increases the efficiency of the wind-solar installation of autonomous power supply.

The use of a voltage comparator with a power transistor allows to optimize the operation of both the synchronous generator and the battery with a battery charge controller when they are working simultaneously. 
The use of a synchronous generator on permanent magnets with a double-circuit magnetic system can reduce the cost of both the autonomous power supply system as a whole, and the cost of the electricity generated.

According to the results of computer simulation, a model with designation of the cross section, in which the value of magnetic induction was measured, is presented in Figure 3.

As a result of computer simulation, the following values of magnetic induction in the middle of the stator windings of the generator with a two-circuit (1) and single-circuit (2) magnetic system are obtained, the results are shown in Figure 4.

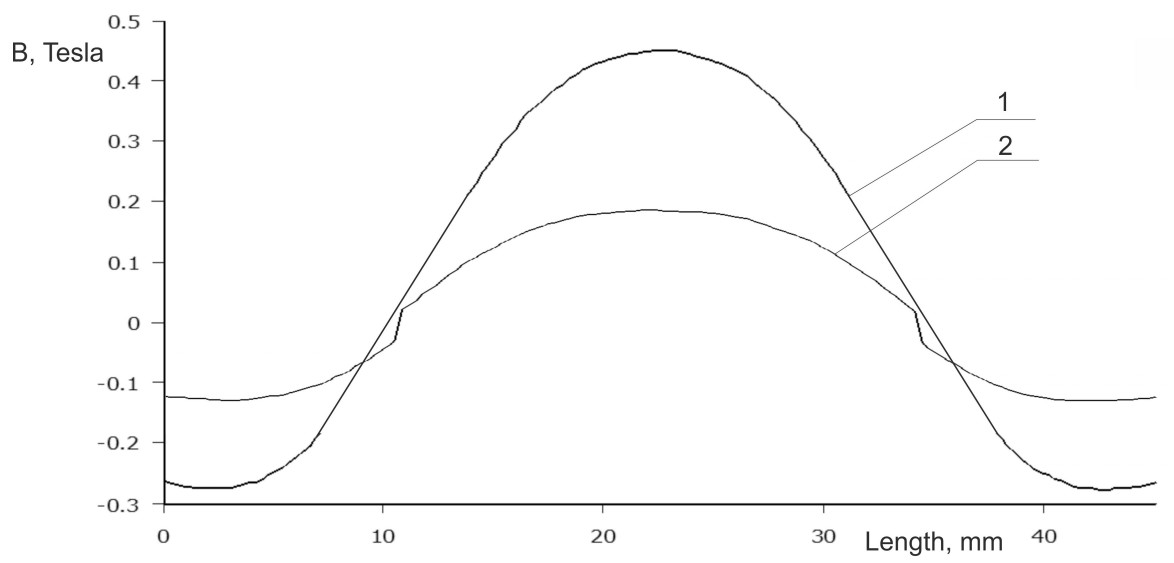

Fig. 4. Magnetic induction in the middle of stator windings with double-circuit (1) and singlecircuit (2) synchronous generator magnetic system

As it can be seen from Figure 3, introduction of a second magnetic circuit (internal) increases the value of magnetic induction in the middle of the coil from 0.19 to 0.44 Tesla, indicating an increase of $130 \%$. The increase in magnetic induction in the stator windings leads to an increase in the power and efficiency of the generator with constant overall performance. The energy of the magnetic field in the stator windings with the introduction of the second magnetic circuit increases by $113 \%$, the use of pseudopoluses in this configuration leads to an increase in the energy of the magnetic field in the stator windings by $65.3 \%$.

To confirm the obtained theoretical data, a synchronous generator was created, the external and internal rotor of which is printed out of plastic on a 3D printer, a magnetic system with neodymium magnets is fixed on the rotors, the stator of the generator is installed between the rotors, as shown in Figure 5.

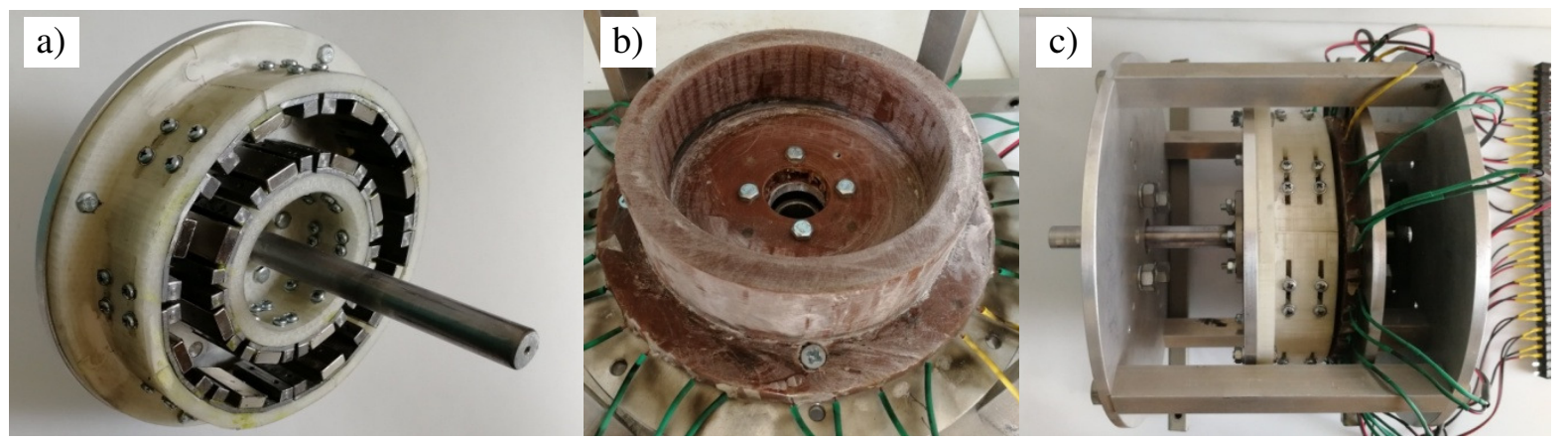

Fig. 5. Rotor of synchronous generator (a), stator of synchronous generator

(b) generator assy (c)

The appearance of the experimental setup is shown in Figure 6. The experimental installation contains a drive motor that simulates the operation of the wind wheel, connected by a flexible coupling with the synchronous generator, an active electric load, measuring instruments.

The results of the studies of the synchronous generator with an internal circuit (1), external circuit (2) and two circuits (3) are shown in Figure 7. The results of the experimental studies were processed 
using the program Statistica, repeated experiments -5 times, rejection of erroneous results was carried out according to the rule $3 \sigma$.

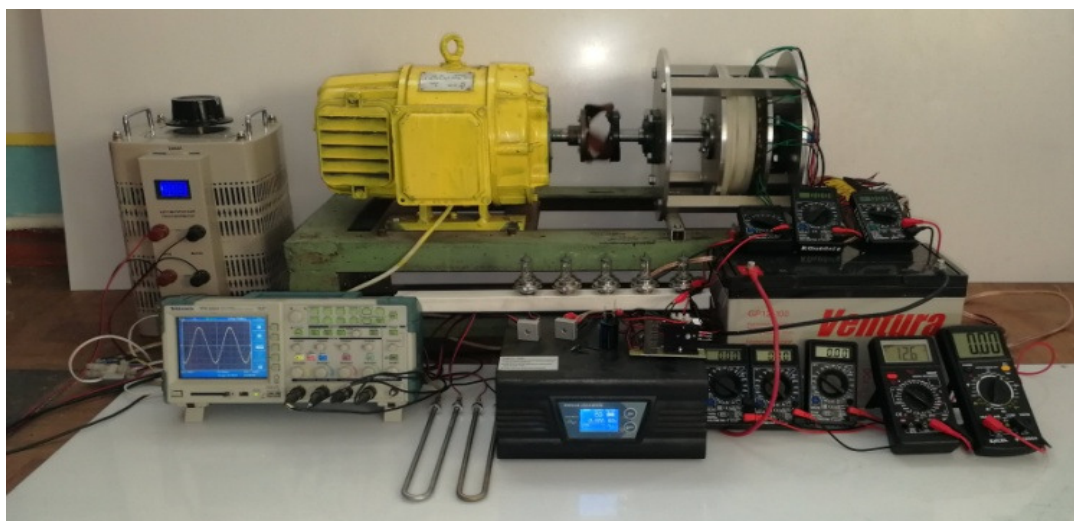

Fig. 6. Experimental setup

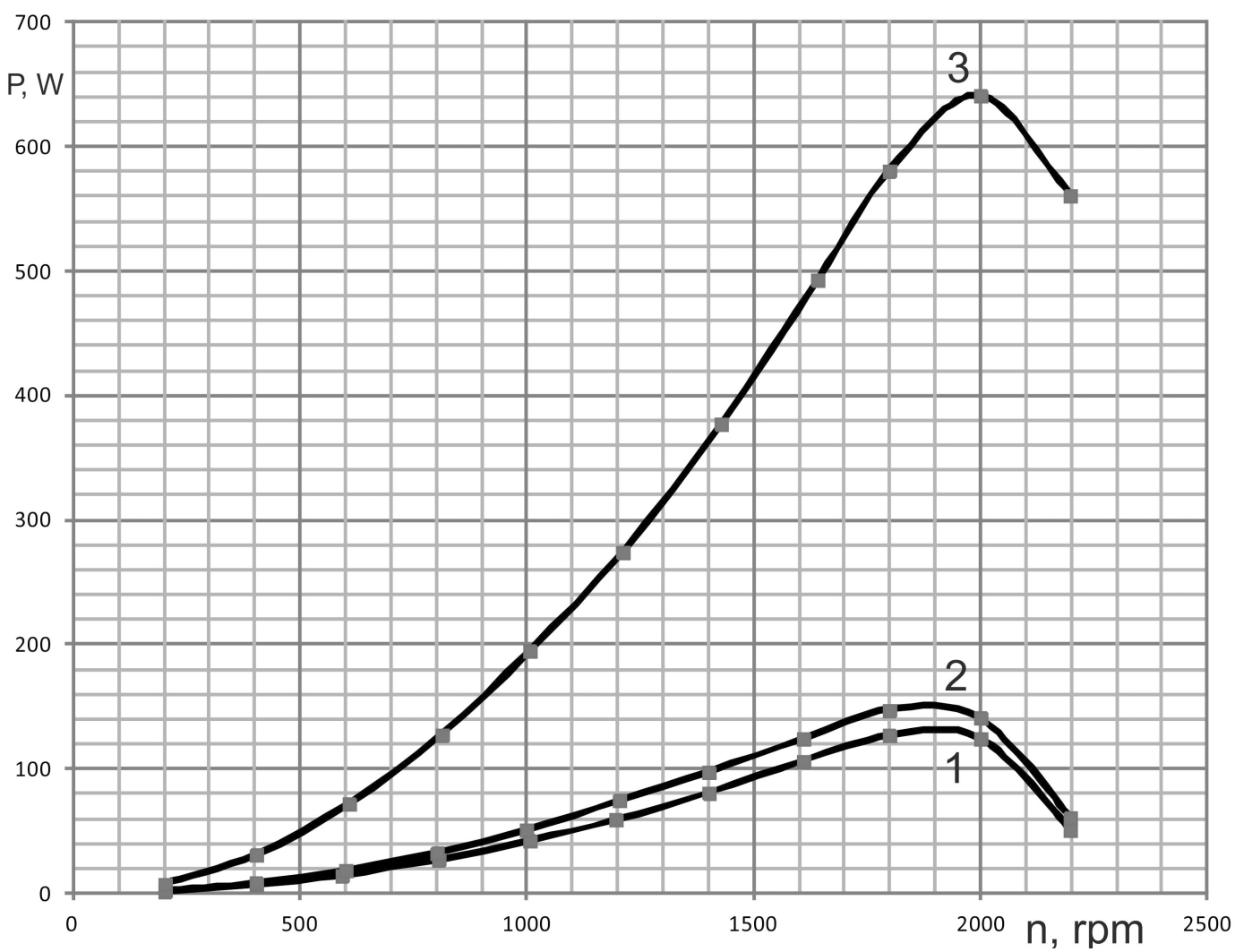

Fig. 7. Power of synchronous generator

When using a two-circuit magnetic system, the generator power increases by about 4 times, which is due to the concentration of the magnetic flux in the stator windings of the generator.

\section{Conclusions}

1. Combined use of various energy sources can improve the reliability of power supply, increase the energy efficiency of the system, reduce the consumption of fuels and lubricants, provide electricity to consumers up to $2 \mathrm{~kW}$.

2. The use of a solar cracker allows to increase power generation by solar panels by $40 \%$ compared to their stationary placement.

3. The use of two magnetic circuits in the synchronous generator design allowed to increase the value of the magnetic induction vector in the generator winding from 0.19 to 0.44 Tesla compared to the single-circuit magnetic system, which led to an increase in the generator power from $150 \mathrm{~W}$ to $640 \mathrm{~W}$. 


\section{References}

[1] Razmjoo A., Shirmohammadi R., Davarpanah A., Pourfayaz F., Aslani A. Stand-alone hybrid energy systems for remote area power generation. Energy Reports vol. 5, 2019. pp. 231-241.

[2] Samikannu R., Sampath Kumar V., Diarra B., Ravi R. Cost optimization and development of hybrid energy systems for rural areas in Ethiopia with a balance of their energy need and resources availability (a case study-on TulUDIMTU). Journal of Testing and Evaluation vol. 47(6), 2019, JTE20180462.

[3] Sun W., Harrison G.P. Wind-solar complementarity and effective use of distribution network capacity. Applied Energy vol. 247,2019, pp. 89-101.

[4] Al-Dousari A., Al-Nassar W., Al-Hemoud A., Al-Dousari N., Ahmed M. Solar and wind energy: Challenges and solutions in desert regions. Energy, vol. 176, 2019, pp. 184-194.

[5] Pat. 2680642 Russian Federation, IPC F03D 9/00, F03D 9/11, F03D 7/00, H02S 10/12 wind-solar installation Autonomous power supply / Nikitenko G. V., Konoplev V. E., Salpagarov K. V., Konoplev, P. V., Bobryshev V. A., Lysakov A. A.; applicant and patent holder FGBOU IN Stavropol GAU. No. 2018103296; application. 29.01.18; publ. 25.02.19, Byul. No. 6.

[6] Pat. 2680642 Russian Federation, IPC H02K 1/27, H02K 21/12, H02K 16/02 Synchronous generator with dual magnetic system / Nikitenko G. V., Konoplev V. E., Salpagarov K. V., Konoplev, P. V., Bobryshev, A. V.; applicant and patent holder FGBOU IN Stavropol GAU. No. 2016152824; application. 30.12.16; publ. 25.01.18, Byul. No. 3 . 